\title{
Consumer perceptions of fruit and vegetables serving sizes
}

\author{
Christina M Pollard ${ }^{1, *}$, Alison M Daly ${ }^{2}$ and Colin W Binns ${ }^{1}$ \\ ${ }^{1}$ Curtin University of Technology, Kent Street, Bentley 6102, Western Australia, Australia: ${ }^{2}$ Department of Health, \\ Royal Street, East Perth, Western Australia, Australia
}

Submitted 14 December 2007: Accepted 16 April 2008: First published online 12 June 2008

\begin{abstract}
Objective: To assess consumer understanding of fruit and vegetable serving sizes. Design: The Western Australian Health Department launched the Go for $2 \& 5^{\circledR}$ campaign to promote fruit and vegetables in March 2002. The Health \& Wellbeing Surveillance System surveyed 1108 adults, aged 16 years and over, between September and November 2002 about what constituted a serving of fruit and of vegetables, their usual daily fruit and vegetables intake, and their recall of the campaign.

Setting: The study was undertaken as a part of a public health intervention - social marketing campaign in Western Australia, which had a population of 1927000 in 2002.

Results: Forty-two per cent of respondents knew that the fruit serving size was one piece and only $14.5 \%$ reported the $\frac{1}{2}$ cup vegetable serving size. The mean fruit intake was $1 \cdot 8(95 \%$ CI $1 \cdot 7,1 \cdot 8)$ servings/d and the mean vegetable intake was $2 \cdot 8(95 \%$ CI $2 \cdot 7,3 \cdot 0)$ servings/d. Vegetable intake was associated with being female $(P=0 \cdot 006)$, increasing age $(P<0.0001)$, awareness of the campaign $(P=0 \cdot 031)$ and knowledge of standard serving size $(P=0 \cdot 006)$. Fruit consumption was associated with being female $(P=0 \cdot 007)$. Fruit and vegetable intakes were not associated with educational attainment or household income. Conclusions: The Go for $2 \& 5^{\circledR}$ campaign uses a prescriptive message to promote increased consumption of fruit and vegetables. Respondent's knowledge of the standard of serving sizes for fruit and vegetables suggests there is value in separating fruit and vegetable recommendations in messages to encourage increased consumption.
\end{abstract}

Regular adequate fruit and vegetable intake contributes to good nutrition and general health and protects against common chronic diseases including $\mathrm{CHD}^{(1-14)}$, hypertension $^{(2,9,15)}$, stroke ${ }^{(6)}$, diabetes $^{(16-21)}$ and some cancers ${ }^{(22)}$, as well as overweight and obesity and a number of other diseases $^{(14)}$. The WHO and FAO have called for nations to increase fruit and vegetable consumption through targeted campaigns $^{(14)}$. Multi-component approaches, addressing individual factors (e.g. knowledge, attitudes, skills, social influences and behaviours) as well as environmental factors (e.g. access, cost, quality and supply), appear to be more effective $^{(23-27)}$. There is a lack of published information about the effectiveness of population-based interventions promoting fruits and vegetables ${ }^{(24)}$.

Health communication 'has the capacity to create awareness, improve knowledge and induce long-term changes in individual and social behaviours, ${ }^{,(28)}$. There is a need for effective educational messages to encourage the consumption of fruit and vegetables ${ }^{(29,30)}$. Knowledge of the recommended fruit and vegetable intake may be motivational, leading to self-evaluation of intake, influencing social norms and increasing the expectation and approval for that level of consumption (31). There might be agreement on the need to increase fruit and vegetable consumption; however, there are differences between countries in their classification, what constitutes a serving and the recommended servings ${ }^{(32)}$, see Table 1.

The Australian recommendation of at least $675 \mathrm{~g}$ daily (including potatoes) is consistent with the minimum 400-600g daily (excluding potatoes) recommended by health authorities to protect against disease ${ }^{(14,22,33)}$. Australian fruit and vegetable recommendations have been separate since 1994, based on the differing nutrient profiles of fruits and vegetables; the practical aspects of eating them; current household consumption levels; and food supply ${ }^{(34)}$. Australia's food selection guide, The Australian Guide to Healthy Eating ${ }^{(35)}$, is incorporated into Australian dietary guidelines ${ }^{(36-38)}$ and is used as the basis for most nutrition education initiatives.

Developing suitable messages to assist consumers to understand and accept the importance of healthy eating is complex. The way in which recommended food intake 


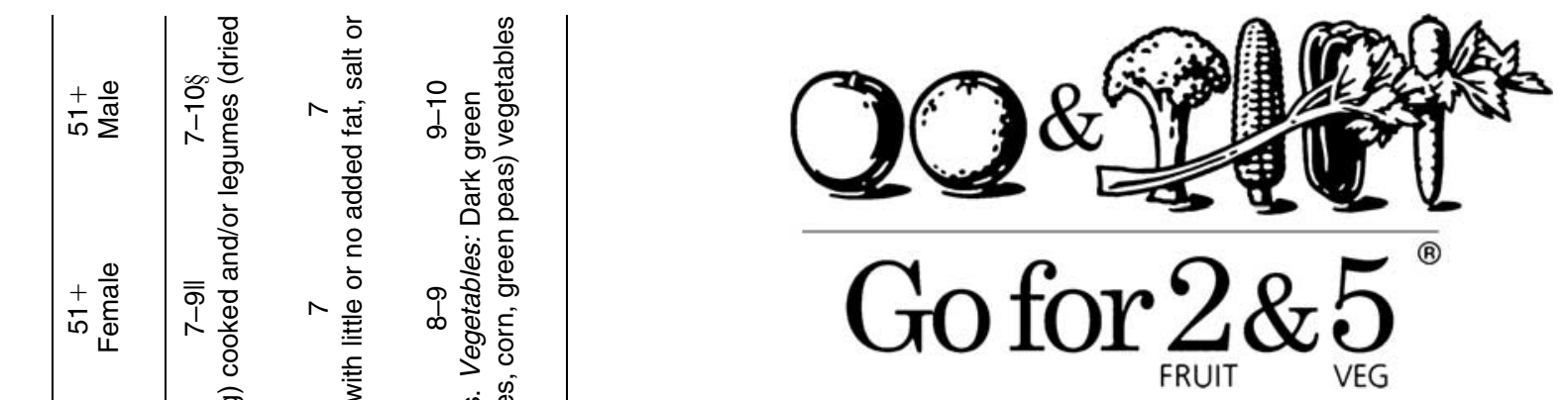

Fig. 1 Go for $2 \& 5^{\circledR} \operatorname{logo}$

amounts are presented, as number of servings or specified size, is often misinterpreted by consumers ${ }^{(39)}$. Focus group research to assist the development of educational messages for the American MyPyramid Food Guidance System found people considered fruits and vegetables should be part of a healthy diet; however, they were confused about serving sizes and the recommended daily intake ${ }^{(39)}$.

The '5-a-day' message has been used as part of campaigns to encourage increased fruit and vegetable consumption $^{(40-42)}$. Consumer research suggests that the $5+$ a-day' message is understood and appropriate to encourage increased frequency of consumption; however, consumers have a limited understanding of servings size ${ }^{(40,41)}$. The Western Australian Health Department (WAHD) developed the Fruit ' $n$ ' Veg with Every Meal social marketing campaign to encourage fruit and vegetable consumption in 1990. Evaluation found that although consumers were aware of the campaign and interpreted the message as needing to eat more fruit and vegetables, they were not prompted to action $^{(43)}$, suggesting that a message specifying an optimal intake was preferable to one saying 'just eat more'.

The Go for $2 \& 5^{\circledR}$ social marketing campaign launched in March 2002 with mass media advertising (television, radio, press and point-of-sale), public relations, publications, website (www.gofor2and5.com), and school and community activities ${ }^{(44)}$. The campaign increased awareness of the need to eat more fruit and vegetables by increasing knowledge of the recommended number of servings, with a corresponding increase in consumption ${ }^{(44)}$. The Go for $2 \& 5^{\circledR} \operatorname{logo}$ mnemonic device reminded consumers of the target (Fig. 1).

The objective of the present study was to determine consumer understanding of what constitutes a serving and the relationship to current fruit and vegetable intake. The timing of the research, six months into a high-profile social marketing campaign, allows analysis of the association between serving size understanding and campaign awareness.

\section{Methods}

In March 2002, the WAHD commenced the Health \& Wellbeing Surveillance System (HWSS) continuous data 
collection system. Computer-assisted telephone interview was used to interview over 550 Western Australian people aged 16 years and over each month. The survey asked about a range of issues including health conditions, lifestyle risk factors, protective factors and sociodemographics. Monthly samples were extracted using the Electronic White Pages telephone numbers as the sample frame and stratifying by rural, remote and metropolitan areas. Within each stratum, random samples were selected. From mid-September until the end of November 2002, all respondents over 16 years ( $n$ 1108) were asked four additional questions relating to fruit and vegetable serving size and campaign awareness.

Respondents were asked, 'What do you think a serve of vegetables/[fruit] equals?'; no alternatives were given and there was no prompting. Responses were then coded into pre-designated categories (one piece, one type, e.g. apple or carrot, $\frac{1}{2}$ cup, other amount [Specify], 'what I put on my plate' [vegetables], other [Specify] or don't know).

Next they were asked about their usual fruit and vegetable intake: 'How many serves of vegetables/[fruit] do you usually eat each day? A serve of vegetable is equal to $\frac{1}{2}$ cup of cooked vegetables or 1 cup of salad' and 'A serve of fruit is equal to one medium piece, two small pieces of fruit or one cup of diced fruit'. They were then asked about awareness of the campaign; 'The Department of Health has recently conducted a campaign about fruit and vegetables. Do you recall hearing or seeing anything about this?'

Prevalence and mean estimates, with 95\% CI, were calculated using the Statistical Package for the Social Sciences version 15.0.1 (SPSS Inc., Chicago, IL, USA). Generalised linear models analysis was conducted using the survey data analysis module ${ }^{(45)}$ in STATA 10 (StataCorp, College Station, TX, USA). Differences were reported as statistically significant when the confidence intervals did not overlap, where they are reported. Inferential statistical analyses provide $P$ values as the basis for statistical significance. The WAHD-approved research met standard social marketing research criteria.

\section{Results}

The final sample of adults aged 16 years and over represents $81 \%$ of contacts made. The data were weighted to correct for over-sampling in rural and remote areas and then adjusted to the age and sex distribution of the Western Australian Estimated Resident Population for 2002.

\section{Knowledge of fruit serving size}

Table 2 displays the self-reported serving size for fruit and vegetables. Most respondents, 83\%, nominated a serving size for fruit. More men (22\%) than women (12\%) said they were unsure about the fruit serving size and there were no significant differences based on age. 'One piece' was the

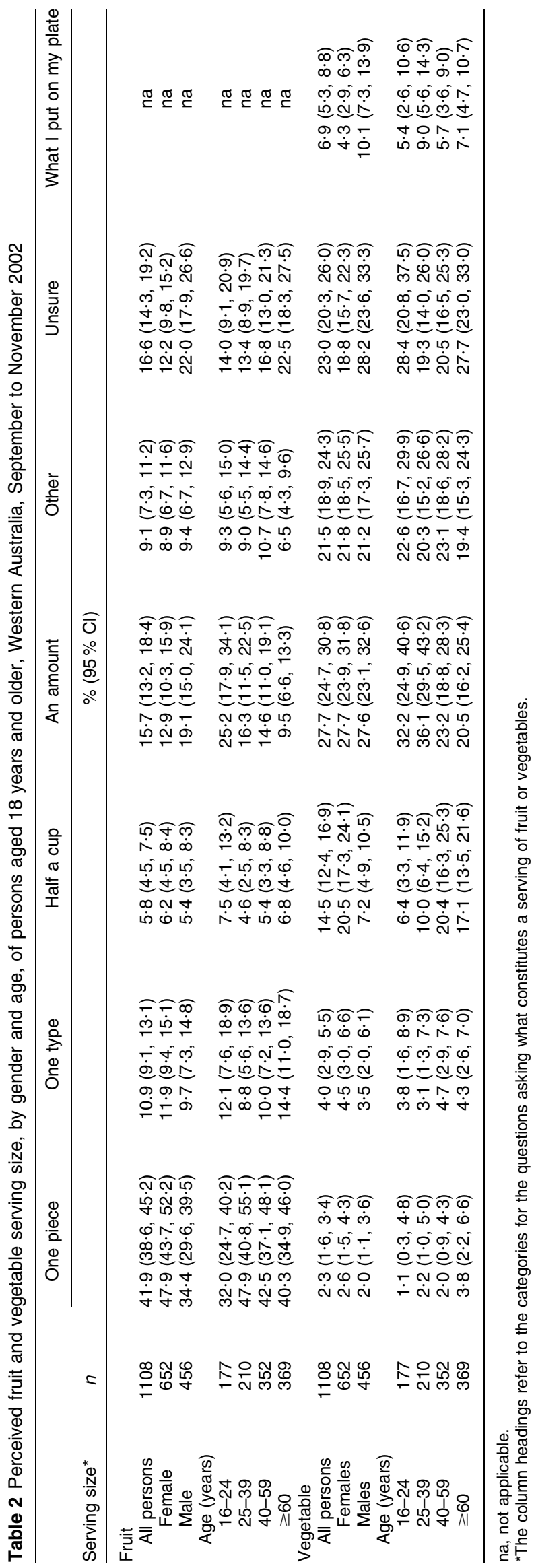


most commonly identified serving size for fruit (42\%), with women (48\%) more likely than men (34\%) to suggest it. People aged 16-24 years were least likely to select 'one piece', $32 \%$ compared to $48 \%$ of 25 - to 39 -year-olds.

'One type of fruit' was identified as the serving size for fruit by $11 \%$ of respondents, with no significant difference based on gender or age. Other serving size amounts were specified by $16 \%$ of respondents.

\section{Knowledge of vegetable serving size}

Table 2 displays the self-reported serving size for vegetables. Most respondents, 78\%, thought they knew the vegetable serving size. Significantly more men than women said they were unsure about the vegetable serving size, $28 \%$ and $19 \%$, respectively. There were no significant differences based on age. Fourteen per cent of respondents, $20 \%$ of women and $7 \%$ of men identified ' $\frac{1}{2}$ cup' (the standard vegetable serving size). People over 40 years old were more likely to identify ' $\frac{1}{2}$ cup' than those who were younger. Twenty-eight per cent of respondents nominated a different amount for the vegetable serving size. Respondents less than 40 years old were more likely than those aged over 40 to specify a different amount. Men (10\%) were more likely than women (4\%) to identify 'the amount I put on my plate' as a serving of vegetables.

\section{Fruit and vegetable consumption}

Table 3 displays knowledge of standard serving size by the mean fruit and vegetable intake. The mean fruit intake was $1.8(95 \%$ CI $1.7,1.8)$ servings/d, with women consuming more than men, 1.9 (95\% CI $1 \cdot 8,2 \cdot 0)$ and 1.6 (95\% CI $1.5,1.7)$ servings/d, respectively. Those who knew the standard fruit serving size had higher intakes, 1.9 compared to 1.7 servings/d; however, the difference was not significant. Respondents who knew the standard serving size for fruit were more likely to eat the recommended two servings per day than who did not, $57 \cdot 2 \%$ $(95 \%$ CI $52 \cdot 0,62 \cdot 2)$ compared to $46 \cdot 3 \%$ (95\% CI $42 \cdot 0$, 50.7).

The mean vegetable intake was $2 \cdot 8$ (95\% CI $2 \cdot 7,3 \cdot 0)$ servings/d. Women had higher intake than men, $3 \cdot 1$ (95\% CI $2 \cdot 9,3 \cdot 0)$ and $2 \cdot 6(95 \%$ CI $2 \cdot 6,2 \cdot 8)$ servings/d, respectively. Men who knew the standard serving size had $1 \cdot 1$ servings more than those who did not. Respondents who knew the standard serving size for vegetables were more likely to have the recommended five servings per day than those who did not, $19 \%$ compared to $11 \%$; however, the difference was not significant. Women who knew the standard serving size for vegetables were more likely to eat five or more servings daily than men who knew the standard serving size, $22 \%$ compared to

Table 3 Daily fruit and vegetable consumption, by serving size and gender, of persons aged 18 years and older, Western Australia, September to November 2002

\begin{tabular}{|c|c|c|c|c|}
\hline \multirow{2}{*}{$\begin{array}{l}\text { Consumption levels* } \\
\text { (servings) }\end{array}$} & \multirow[b]{2}{*}{$n$} & Standard serving $\dagger$ & Incorrectł & Unsure \\
\hline & & \multicolumn{3}{|c|}{$\%(95 \% \mathrm{Cl})$} \\
\hline \multicolumn{5}{|l|}{ Fruit } \\
\hline Females & 652 & & & \\
\hline$\geq 2$ servings & & $64 \cdot 2(58 \cdot 0,70 \cdot 0)$ & $54 \cdot 4(47 \cdot 7,61 \cdot 0)$ & $49 \cdot 3(38 \cdot 0,60 \cdot 7)$ \\
\hline$<2$ servings & & $35 \cdot 8(30 \cdot 0,42 \cdot 0)$ & $45 \cdot 6(39 \cdot 0,52 \cdot 3)$ & $50 \cdot 7(39 \cdot 3,62 \cdot 0)$ \\
\hline Mean servings & & $2 \cdot 0(1 \cdot 8,2 \cdot 2)$ & $1 \cdot 9(1 \cdot 7,2 \cdot 0)$ & $1 \cdot 7(1 \cdot 5,2 \cdot 0)$ \\
\hline Males & 456 & & & \\
\hline$\geq 2$ servings & & $45 \cdot 2(36 \cdot 6,54 \cdot 1)$ & $40 \cdot 1(32 \cdot 6,48 \cdot 2)$ & $38 \cdot 6(28 \cdot 8,49 \cdot 4)$ \\
\hline$<2$ servings & & $54 \cdot 8(45 \cdot 9,63 \cdot 4)$ & $59 \cdot 9(51 \cdot 8,67 \cdot 4)$ & $61 \cdot 4(50 \cdot 3,71 \cdot 2)$ \\
\hline Mean servings & & $1 \cdot 7(1 \cdot 4,1 \cdot 9)$ & $1 \cdot 6(1 \cdot 4,1 \cdot 8)$ & $1 \cdot 4(1.5,2 \cdot 0)$ \\
\hline All persons & 1102 & & & \\
\hline$\geq 2$ servings & & $57 \cdot 2(52 \cdot 0,62 \cdot 2)$ & $47 \cdot 7(42 \cdot 5,52 \cdot 9)$ & $42 \cdot 8(35 \cdot 3,51 \cdot 0)$ \\
\hline$<2$ servings & & $42 \cdot 8(37 \cdot 8,48 \cdot 0)$ & $52 \cdot 3(47 \cdot 1,57 \cdot 5)$ & $57 \cdot 1(49 \cdot 0,64 \cdot 7)$ \\
\hline Mean servings & & $1.9(1 \cdot 7,2 \cdot 0)$ & $1 \cdot 7(1 \cdot 6,1 \cdot 9)$ & $1.5(1.4,1 \cdot 7)$ \\
\hline Knowledge of serving size & & $41 \cdot 8(38 \cdot 6,45 \cdot 2)$ & $41 \cdot 5(38 \cdot 3,44 \cdot 9)$ & $16 \cdot 6(14 \cdot 3,19 \cdot 2)$ \\
\hline \multicolumn{5}{|l|}{ Vegetables } \\
\hline Females & 652 & & & \\
\hline$\geq 5$ servings & & $22 \cdot 3(15 \cdot 6,30 \cdot 9)$ & $13 \cdot 7(10 \cdot 4,17 \cdot 9)$ & $15 \cdot 9(10 \cdot 1,24 \cdot 2)$ \\
\hline$<5$ servings & & $77 \cdot 7(69 \cdot 1,84 \cdot 4)$ & $86 \cdot 3(82 \cdot 1,89 \cdot 6)$ & $84 \cdot 1(75 \cdot 8,89 \cdot 9)$ \\
\hline Mean servings & & $3.5(3.2,3.8)$ & $3 \cdot 0(2 \cdot 8,3 \cdot 2)$ & $2 \cdot 8(2 \cdot 5,3 \cdot 1)$ \\
\hline Males & 456 & & & \\
\hline$\geq 5$ servings & & $8 \cdot 7(2 \cdot 1,30 \cdot 4)$ & $13 \cdot 8(9 \cdot 9,18 \cdot 9)$ & $6 \cdot 6(3 \cdot 2,13 \cdot 0)$ \\
\hline$<5$ servings & & $91 \cdot 3(69 \cdot 6,97 \cdot 9)$ & $86 \cdot 2(81 \cdot 1,90 \cdot 1)$ & $93 \cdot 4(87 \cdot 0,96 \cdot 8)$ \\
\hline Mean servings & & $3 \cdot 2(2 \cdot 8,3 \cdot 6)$ & $2 \cdot 7(2 \cdot 4,2 \cdot 9)$ & $2 \cdot 1(1 \cdot 8,2 \cdot 4)$ \\
\hline All persons & 1102 & & & \\
\hline$\geq 5$ servings & & $19 \cdot 3(13 \cdot 5,26 \cdot 8)$ & $13 \cdot 7(11 \cdot 1,16 \cdot 9)$ & $10 \cdot 8(7 \cdot 3,15 \cdot 7)$ \\
\hline$<5$ servings & & $80 \cdot 7(73 \cdot 2,86 \cdot 5)$ & $86 \cdot 3(83 \cdot 1,88 \cdot 9)$ & $89 \cdot 2(84 \cdot 3,92 \cdot 7)$ \\
\hline Mean servings & & $3.5(3.2,3.7)$ & $2 \cdot 8(2 \cdot 7,3 \cdot 0)$ & $2 \cdot 4(2 \cdot 2,2 \cdot 6)$ \\
\hline Knowledge of serving size & & $14 \cdot 5(12 \cdot 4,16 \cdot 9)$ & $62 \cdot 5(59 \cdot 2,65 \cdot 7)$ & $23 \cdot 0(20 \cdot 3,26 \cdot 0)$ \\
\hline
\end{tabular}

*The consumption levels are equal to or above/below the recommended Australian guidelines of at least two servings of fruit and five servings of vegetables per day.

tOne piece of fruit or $\frac{1}{2}$ cup of vegetables.

$\ddagger$ Another amount or 'other'. 
Table 4 Parameter estimates by number of servings of fruit (vegetables) consumed per day of persons aged 18 years and older, Western Australia, September to November 2002

\begin{tabular}{|c|c|c|c|c|c|}
\hline \multirow[b]{2}{*}{ Parameter } & \multirow[b]{2}{*}{ Coefficient } & \multirow[b]{2}{*}{$t$} & \multirow[b]{2}{*}{$P>[t]$} & \multicolumn{2}{|c|}{$95 \% \mathrm{Cl}$} \\
\hline & & & & Lower & Upper \\
\hline \multicolumn{6}{|l|}{ Number of vegetable servings per day } \\
\hline Gender & -0.41 & $-2 \cdot 74$ & 0.006 & $-0 \cdot 71$ & $-11 \cdot 67$ \\
\hline Age group & 0.34 & $3 \cdot 85$ & 0.000 & $0 \cdot 17$ & 0.52 \\
\hline Knowledge of the campaign & $0 \cdot 33$ & $2 \cdot 16$ & 0.031 & 0.03 & 0.64 \\
\hline Recognition of the vegetable face & $0 \cdot 12$ & -0.57 & 0.569 & -0.52 & 0.29 \\
\hline Knowledge of serving size & 0.52 & $2 \cdot 77$ & 0.006 & $0 \cdot 15$ & 0.89 \\
\hline Household income & 0.05 & 0.86 & $0 \cdot 388$ & -0.06 & $0 \cdot 16$ \\
\hline Education & 0.56 & $1 \cdot 02$ & $0 \cdot 308$ & -0.05 & $0 \cdot 16$ \\
\hline \multicolumn{6}{|l|}{ Number of fruit servings per day } \\
\hline Gender & -0.29 & $-2 \cdot 71$ & 0.007 & -0.50 & -0.01 \\
\hline Age group & $0 \cdot 13$ & 0.48 & 0.632 & $-0 \cdot 16$ & 0.26 \\
\hline Knowledge of the campaign & 0.05 & 0.48 & 0.632 & $-0 \cdot 16$ & 0.27 \\
\hline Recognition of the vegetable face & $-0 \cdot 11$ & -365 & 0.516 & -0.45 & 0.23 \\
\hline Knowledge of serving size & 0.07 & 0.61 & 0.544 & $-0 \cdot 16$ & 0.29 \\
\hline Household income & 0.06 & 1.56 & $0 \cdot 119$ & $-0 \cdot 15$ & $0 \cdot 13$ \\
\hline Education & 0.03 & $0 \cdot 72$ & 0.474 & -0.06 & $0 \cdot 12$ \\
\hline
\end{tabular}

Analysis done using STATA 10 survey data analysis module, generalised linear models.

$9 \%$, respectively. Respondents who were aware of the campaign reported higher mean vegetable intake than those who were not, $3 \cdot 0(95 \%$ CI $2 \cdot 8,3 \cdot 1)$ compared to $2 \cdot 5(95 \%$ CI $2 \cdot 3,2 \cdot 7)$ servings/d, respectively. There was no significant difference for fruit consumption. Table 4 displays factors influencing fruit and vegetable consumption. Vegetable intake was significantly associated with being female $(P=0 \cdot 006)$, increasing age $(P<0 \cdot 0001)$, awareness of the campaign $(P=0 \cdot 031)$, and knowledge of standard serving size $(P=0 \cdot 006)$. Fruit consumption had a significant association with gender $(P=0 \cdot 007)$. There were no significant associations based on educational attainment or household income.

\section{Discussion}

Developing suitable messages to assist consumers to understand and accept the importance of healthy eating is complex. Knowledge gaps associated with the recommendation to eat more fruit and vegetables were evident in this study, particularly for vegetables. Knowledge of the recommended amount may reflect a key skill needed to perform the behaviour, it may serve a motivational function leading to a self-evaluation of intake, and it may provide a normative influence, increasing the expectation and approval for that level of consumption ${ }^{(31)}$. To understand dietary recommendations, consumers needed to know the type and amount of recommended foods, and to assess the adequacy of their current intake they needed to know what constituted a serving ${ }^{(39)}$. Britten et al. (2006) found consumers could apply this information by mentally adding up the amounts they consumed at each meal and comparing it to daily recommendations ${ }^{(39)}$. Overly optimistic assessment of current intakes results in complacency about the need to eat more fruit and vegetables $^{(44,46,47)}$. Respondents were more confident in assigning a serving size to fruit than to vegetables. The most common fruit serving size of 'one piece' supports the finding that consumers prefer recommendations expressed in pieces of fruit ${ }^{(39)}$. Respondents reported vegetable serving sizes in 'amounts', consistent with previous findings that common household units or measures, for example a cup, were preferred for vegetables ${ }^{(39)}$.

Many theoretical models can be used to guide food choice research $^{(48,49)}$. The Go for $2 \& 5^{\circledR}$ campaign used a model of adapted phases between knowledge and behaviour $^{(50,51)}$ to examine behavioural beliefs, attitudes, influencers and intentions ${ }^{(44)}$. How or whether consumers use serving size information to make their food choices is still not clear; however, the information may be useful to assist with the assessment of current intake. Policy recommendations and assessment of intervention effectiveness rely on accurate dietary assessment. The measurement method influences the proportion of the population categorised as meeting fruit and vegetable guidelines ${ }^{(52-54)}$.

The main strength of the present study is that it provides a quantified population-level snapshot of consumer understanding of fruit and vegetable serving sizes six months after the commencement of the Go for $2 \& 5^{\circledR}$ campaign. The results are representative of the Western Australian population as a whole but may not represent subgroups within the population, such as Aboriginal people. There were also study limitations, the analysis did not distinguish amounts other than ' $\frac{1}{2}$ cup'; other amounts, particularly for vegetables, are required. Additional questions relating to knowledge of recommended intake, or asking current intake before and after defining serving sizes are suggested; however, minimal additional questions can be added to an existing surveillance system. Knowledge of serving size or dietary behaviour may merely be a marker for a cluster of 'healthy lifestyle' 
behaviours (e.g. smoking, exercise). Recent New Zealand research found little or no clustering of healthy behaviours, and refuted that fruit and vegetable consumption is merely a marker of healthy lifestyle ${ }^{(55)}$. Further analysis to determine the influence of other lifestyle factors is suggested. More community education is required on serving size to maximise the impact of health promotion campaigns such as the Go for $2 \& 5^{\circledR}$. More research is required to establish the best method for this education.

\section{Conclusions}

Consumers differentiate between serving sizes for fruit and vegetables. Knowledge of the standard fruit and vegetable serving sizes is related to the consumption of the recommended amounts. Respondents' understanding of fruit and vegetable serving sizes suggests it is important to separate fruit and vegetable recommendations, using common household measures to convey serving sizes, and using prescriptive messages, for example Go for $2 \& 5^{\circledR}$ to encourage fruit and vegetable consumption.

\section{Acknowledgements}

Funding source: The development, implementation and evaluation of the Go for $2 \& 5^{\circledR}$ campaign was funded by the Western Australian Health Department (WAHD). Horticulture Australia Limited funded Curtin University of Technology to assist with the preparation of publications. The WAHD developed and owns the Intellectual Property for the Go for $2 \& 5^{\circledR}$ campaign.

Conflict of interest: Nil.

Author contributions: A.M.D. and C.M.P. worked for the WAHD who funded independent market research companies to conduct the HWSS survey and produce original data sets. None of the authors were involved in any interviews. C.M.P. was also responsible for managing the development, implementation and evaluation of the Go for $2 \& 5^{\circledR}$ fruit and vegetable campaign.

Acknowledgements: The authors acknowledge the staff at the former Nutrition, Marketing and Communications Branches of the Health Promotion Directorate and the Health Information Centre at the WAHD; and 303 Advertising Agency (who developed the creative and campaign strategy). The WAHD contracted independent market research companies to administer each survey. Horticulture Australia Limited (HAL) supported Curtin University of Technology to analyse the data and prepare papers for publication.

\section{References}

1. Australian Institute of Health and Welfare (2006) Chronic Diseases and Associated Risk Factors in Australia Cat. no. PHE 81. Canberra: AIHW.
2. Bazzano LA (2006) The high cost of not consuming fruits and vegetables. J Am Diet Assoc 106, 1364-1368.

3. Bazzano LA (2005) Dietary Intake of Fruit and Vegetables and Risk of Diabetes Mellitus and Cardiovascular Diseases. Geneva: WHO.

4. Dauchet L, Amouyel P, Hercberg S \& Dallongeville J (2006) Fruit and vegetable consumption and risk of coronary heart disease: a meta-analysis of cohort studies. J Nutr 136, 2588.

5. Epping-Jordan JE, Galea G, Tukuitonga C \& Beaglehole R (2005) Preventing chronic diseases: taking stepwise action. Lancet 366, 1667-1671.

6. Gillman MW, Cupples LA, Gagnon D, Posner BM, Ellison RC, Castelli WP \& Wolf PA (1995) Protective effect of fruits and vegetables on development of stroke in men. JAMA 12, 1113-1117.

7. Hu FB (2003) Plant-based foods and prevention of cardiovascular disease: an overview. Am J Clin Nutr $\mathbf{7 8}$, 544S-551S.

8. Hung H-C, Joshipura KJ, Jiang R, Hu FB, Hunter D, SmithWarner SA, Colditz GA, Rosner B, Spiegelman D \& Willett WC (2004) Fruit and vegetable intake and risk of major chronic disease. J Natl Cancer Inst 3, 1577-1584.

9. Miura K, Greenland P, Stamler J, Liu K, Daviglus ML \& Nakagawa H (2004) Relation of vegetable, fruit, and meat intake to 7-year blood pressure change in middle-aged men. Am J Epidemiol 159, 572.

10. Ness AR \& Powles JW (1997) Fruit and vegetables, and cardiovascular disease: a review. Int J Epidemiol 26, 1-13.

11. Pomerleau J, Lock K \& McKee M (2006) The burden of cardiovascular disease and cancer attributable to low fruit and vegetable intake in the European Union: differences between old and new Member States. Public Health Nutr 9, 575-583.

12. Tobias M, Turley M, Stefanogiannis N, Vander Hoorn S, Lawes C, Ni Mhurchu C \& Rodgers A (2006) Vegetable and fruit intake and mortality from chronic disease in New Zealand. Aust N Z J Public Health 30, 26-31.

13. Van Duyn MAS \& Pivonka E (2000) Overview of the health benefits of fruit and vegetable consumption for the dietetics professional: selected literature. J Am Diet Assoc 100, 1511.

14. World Health Organization (2003) Diet, Nutrition and the Prevention of Chronic Disease. WHO Technical Report Series no. 916. Geneva: WHO.

15. Svetky LP, Simons-Morton DG \& Vogt TM (1999) Effects of dietary patterns on blood pressure: Subgroup analysis of the DASH randomised clinical trials. Arch Intern Med 159, 285-293.

16. Colditz GA, Manson JE, Stampfler MJ \& Rosner B (1992) Diet and risk of clinical diabetes in women. Am J Clin Nutr 55, 1018-1023.

17. Feskens EJM, Virtanen SM, Rasanen L \& Tuomilehto J (1995) Dietary factors determining diabetes and impaired glucose tolerance. Diabetes Care 18, 1104-1112.

18. Ford ES \& Mokdad AH (2001) Fruit and vegetable consumption and diabetes mellitus incidence among US adults. Prev Med 32, 33-39.

19. Sargeant LA, Khaw KT, Bingham S, Day NE, Luben RN, Oakes S, Welch A \& Wareham NJ (2001) Fruit and vegetable intake of population glycosylated haemoglobin levels: the EPIC-Norfolk Study. Eur J Clin Nutr 55, 342.

20. Snowdon DA \& Phillips RK (1985) Does a vegetarian diet reduce the occurrence of diabetes? Am J Public Health $\mathbf{7 5}$, 507-512.

21. Williams DE, Wareham NJ \& Cox BD (1999) Frequent salad consumption is associated with reduction in the risk of diabetes mellitus. J Clin Epidemiol 52, 329-335.

22. World Cancer Research Fund/American Institute of Cancer Research (2007) Food, Nutrition, Physical Activity, and the Prevention of Cancer: a Global Perspective. Washington, DC: WRCF/AICR. 
23. Glanz K \& Hoelscher D (2004) Increasing fruit and vegetable intake by changing environments, policy and pricing: restaurant-based research, strategies, and recommendations. Prev Med 39, Suppl. 2, S88-S93.

24. Pomerleau J, Lock K, Knai C \& McKee M (2005) Effectiveness of Interventions and Programmes Promoting Fruit and Vegetable Intake: Geneva: WHO.

25. Pomerleau J, Lock K, Knai C \& McKee M (2005) Interventions designed to increase adult fruit and vegetable intake can be effective: a systematic review of the literature. J Nutr 135, 2486-2495.

26. Knai C, Pomerleau J, Lock K \& McKee M (2006) Getting children to eat more fruit and vegetables: a systematic review. Prev Med 42, 85-95.

27. van der Horst K, Oenema A, Ferreira I, Wendel-Vos W, Giskes K, van Lenthe F \& Brug J (2007) A systematic review of environmental correlates of obesity-related dietary behaviors in youth. Health Educ Res 22, 203-226.

28. World Health Organization (2003) World Health Assembly Resolution WHA57.17 - Global Strategy on Diet, Physical Activity and Health. Geneva: WHO.

29. Ledikwe JH, Ello-Martin JA \& Rolls BJ (2005) Portion sizes and the obesity epidemic. J Nutr 135, 905-909.

30. Lea EJ, Crawford D \& Worsley A (2006) Public views of the benefits and barriers to the consumption of a plant-based diet. Eur J Clin Nutr 60, 828-837.

31. Reynolds KD, Bishop DB, Chou C-P, Xie B, Nebeling L \& Perry CL (2004) Contrasting mediating variables in two 5-a-day nutrition intervention programs. Prev Med 39, 882-893.

32. Miller M, Pollard C \& Coli T (1997) Western Australian Health Department recommendations for fruit and vegetable consumption - how much is enough? Aust $N Z \mathrm{~J}$ Public Health 21, 638-642.

33. Lock K, Pomerleau J, Causer L, Altmann DR \& McKee M (2005) The global burden of disease attributable to low consumption of fruit and vegetables: implications for the global strategy on diet. Bull World Health Organ 83, $100-108$.

34. Cashel K \& Jefferson S (1994) The Core Food Groups. The Scientific Basis for Developing Nutrition Education Tools. National Health and Medical Research Council. Canberra: Australian Government Publishing Service.

35. Smith A, Kellett E, Schmerlaib Y \& Smith B (1999) Development of the Australian Guide to Healthy Eating 1: Background and rationale. Aust J Nutr Diet 56, 188-193.

36. National Health and Medical Research Council (1999) Dietary Guidelines for Older Australians. Canberra: Commonwealth of Australia.

37. National Health and Medical Research Council (2003) Dietary Guidelines for Children and Adolescents in Australia incorporating the Infant Feeding Guidelines for Health Workers. Canberra: Commonwealth of Australia.

38. National Health and Medical Research Council (2003) Dietary Guidelines for Australian Adults. Canberra: Commonwealth of Australia.
39. Britten P, Haven J \& Davis C (2006) Consumer research for development of educational messages for the MyPyramid Food Guidance System. J Nutr Educ Behav 38, S108-S123.

40. Ashfield-Watt PAL (2006) Fruits and vegetables, 5+ a day: are we getting the message across? Asia Pac J Clin Nutr 15, $245-252$

41. Ashfield-Watt PAL, Welch AA, Day NE \& Bingham SA (2004) Is 'five-a-day' an effective way of increasing fruit and vegetable intakes? Public Health Nutr 7, 257-261.

42. Stables G \& Heimendinger J (editors) (2001) 5 a Day for Better Health Program Monograph. Bethesda, MD: National Institutes of Health, National Cancer Institute.

43. Miller M, Pollard C \& Paterson D (1996) Public health nutrition campaigns: Fruit ' $\mathrm{n}$ ' Veg with Every Meal. In Multidisciplinary Approaches to Food Choice [A Worsley, editor]. Adelaide: University of Adelaide.

44. Pollard CM, Miller MR, Daly AM, Crouchley KE, O'Donoghue $\mathrm{KJ}$, Lang AJ \& Binns CW (2008) Increasing fruit and vegetable consumption: success of the Western Australian Go for $2 \& 5^{\circledR}$ campaign. Public Health Nutr 11, 314-320.

45. StataCorp LP (1996) STATA ${ }^{\circledR}$ 10: Data Analysis and Statistical Package, 10th ed. Texas, USA: StataCorp LP.

46. Dibsdall LA, Lambert N, Bobbin RF \& Frewer LJ (2003) Low-income consumers' attitudes and behaviour towards access, availability and motivation to eat fruit and vegetables. Public Health Nutr 6, 159-168.

47. Cox DN, Anderson AS, Lean ME \& Mela DJ (1998) UK consumer attitudes, beliefs and barriers to increasing fruit and vegetable consumption. Public Health Nutr 1, 61-68.

48. Anderson ES, Winett RA \& Wojcik JR (2007) Self-regulation, self-efficacy, outcome expectations, and social support: social cognitive theory and nutrition behavior. Ann Behav Med 34, 304-312.

49. Glanz K (2000) Theory at a Glance. A Guide for Health Promotion Practice. Washington, DC: US Department of Health and Human Services, National Cancer Institute.

50. Fishbein M \& Ajzen I (1975) Belief, Attitude, Intention, and Behavior: An Introduction to Theory and Research. Reading, MA: Addison-Wesley.

51. Egger G (1990) Health Promotion Strategies and Methods. Australia: McGraw-Hill.

52. Michels KB, Welch AA, Luben R, Bingham SA \& Day NE (2005) Measurement of fruit and vegetable consumption with diet questionnaires and implications for analyses and interpretation. Am J Epidemiol 15, 987-994.

53. Field AE, Colditz GA, Fox MK, Byers T, Serdula M, Bosch RJ \& Peterson KE (1998) Comparison of 4 questionnaires for assessment of fruit and vegetable intake. Am J Public Health 88, 1216-1218.

54. Pomerleau J, Lock K, McKee M \& Altmann DR (2004) The challenge of measuring global fruit and vegetable intake. J Nutr 134, 1175-1180.

55. Tobias M, Jackson G, Yeh L-C \& Huang K (2007) Do healthy and unhealthy behaviours cluster in New Zealand? Aust N Z J Public Health 31, 155-163. 